\title{
OS SIGNOS DO POEMA EU, ETIQUETA
}

\author{
Alex Sandro de Araújo Carmo
}

RESUMO: Por meio de extração e análise entre o poema Eu, Etiqueta de Carlos Drummond de Andrade, e os estudos de Mikhail Bakhtin, este trabalho tem como objetivo buscar perceber a concepção de enunciado, signo e ideologia. Para traçar uma linha de entendimento acerca do universo da linguagem e os aspectos ideológicos, utilizar-se-á um viés materialista e dialético. Ressalta-se ainda que, embora seja utilizado neste estudo um poema, não se terá necessariamente uma abordagem literária, pois o principal intuito aqui, é contribuir para uma leitura mais reflexiva de Bakhtin.

PALAVRAS-CHAVE: poema, signo, ideologia.

ABSTRACT:Through extraction and analysis of the poem I label of Carlos Drummond de Andrade, and studies of Mikhail Bakhtin, this work aims to seek to understand the design set out, sign and ideology. To draw a line of understanding about the universe of language and the ideological aspects, use will be a bias materialist and dialectical. It is emphasized that, although it is used in this study a poem, does not necessarily have a literary approach, since the main objective here is to contribute to a more reflective reading of Bakhtin. KEYWORDS: poem, sign, ideology.

\section{Introdução}

Este artigo procurará extrair do poema Eu, Etiqueta de Carlos Drummond de Andrade, por meio de uma análise contextual, elementos que identifiquem certa proximidade com os estudos de Bakhtin, acerca do enunciado, do signo e da ideologia. Antes de salientar sobre os conceitos que serão abordados, ressalta-se que este trabalho não pretende fazer uma análise literária, o que se busca aqui, é propiciar entendimento a termos encontrados na obra de Bakhtin, que mostram a concepção do pensador sobre a linguagem e as relações humanas, visto que ele entendia a linguagem como um instrumento de interação social, onde se visualiza os processos ideológicos. Dê início, apresenta-se os extratos do poema que serão analisados:

Em minha calça está grudado um nome

Que não é meu de batismo ou de cartório

Um nome... estranho.

Meu blusão traz lembrete de bebida

Que jamais pus na boca, nessa vida,

Em minha camiseta, a marca de cigarro

Que não fumo, até hoje não fumei.

Minhas meias falam de produtos

Que nunca experimentei

Mas são comunicados a meus pés.

[...] 
Meu isso, meu aquilo.

Desde a cabeça ao bico dos sapatos,

São mensagens,

Letras falantes,

Gritos visuais,

Ordens de uso, abuso, reincidências.

[...]

E fazem de mim homem-anúncio itinerante,

Escravo da matéria anunciada.

Estou, estou na moda.

É duro andar na moda, ainda que a moda

Seja negar minha identidade,

[...]

Agora sou anúncio

Ora vulgar ora bizarro.

Em língua nacional ou em qualquer língua

(Qualquer principalmente.)

Eu é que mimosamente pago

Para anunciar, para vender

[...]

Saio da estamparia, não de casa,

Da vitrine me tiram, recolocam,

[...]

Meu nome novo é Coisa.

Eu sou a Coisa, coisamente.

(ANDRADE, 1984: 85-87).

Nestes versos, vê-se certa gama de propósitos, que o poeta com muita habilidade marcou ao manusear as palavras. O nome grudado na calça, e que não se conhece, é a etiqueta do produto ou um signo? As estampas contidas no blusão, na camiseta, nas meias, não seriam publicidades gratuitas (que o poeta menciona que se paga ao usar)? Todos os produtos que rodeiam as pessoas são mensagens? E essas mensagens, e o uso de imperativos, denunciados nesses versos, retratam costumes ou ordens? O homem é um veículo de propaganda que tem liberdade de escolha? O ser humano que vive na realidade pronunciada pelo poema, sabe se reconhecer? Sabe se é ser humano ou coisa? Quantas perguntas podem ser formuladas por intermédio deste poema? Este estudo buscará mediar e transparecer alguns fatos relativos a essas questões.

\section{Uma base teórica para o estudo dos enunciados e dos signos}

Este poema, como já mencionado, foi escolhido para este estudo, por causa de sua proximidade aos estudos de Bakhtin, visto que o pensador russo para realizar um estudo concreto sobre a linguagem apontava a necessidade de se observar "o papel produtivo e a natureza social da enunciação" (BAKHTIN, 1999, p. 27), portanto o ponto de partida será a questão da enunciação.

Assim,

A enunciação enquanto tal é um puro produto da interação social, quer se trate de um ato de fala determinado pela situação imediata ou pelo contexto mais amplo que constitui o conjunto das condições de vida de uma determinada comunidade lingüística. (BAKHTIN, 1999, p. 121). 
Veja, a palavra é descrita por Bakhtin em Marxismo e Filosofia da Linguagem como neutra, não comportando nenhuma significação ou valor semiótico, pois quando a palavra absorve valor ou significado já não é mais uma palavra e sim um enunciado. Em Estética da Criação Verbal, o autor, vai mostrar que existem enunciados concretos e únicos, primários e secundários, e que "cada esfera de utilização da língua elabora seus tipos relativamente estáveis de enunciados, sendo isso que denominamos gêneros do discurso." (BAKHTIN, 2000, p. 279). O fato que diferencia um enunciado (gênero de discurso) primário de um secundário, além, de um ser simples e o outro complexo, é que os enunciados secundários aparecem em decorrência da comunicação cultural, na forma de romance, de discurso científico e/ou ideológico e etc., enquanto os primários podem ser vistos como o diálogo cotidiano, a conversa simples sobre os fatos corriqueiros do dia-a-dia. Para fixar melhor:

Em cada época de seu desenvolvimento, a língua escrita é marcada pelos gêneros do discurso e não só pelos gêneros secundários (literários, científicos, ideológicos), mas também pelos gêneros primários (os tipos do diálogo oral: linguagem das reuniões sociais, dos círculos, linguagem familiar, cotidiana, linguagem sociopolítica, filosófica, etc.). (BAKHTIN, 2000, p. 285)

Os gêneros primários (enunciados) quando entram no quadro dos secundários, perdem sua característica particular, pois não pertencem mais a realidade da qual foram originados, agora eles pertencem à realidade dos "enunciados alheios", ou seja, no ato de comunicação social, um enunciado se transforma em outros enunciados (primários ou secundários).

Nessa interação, há duas particularidades do enunciado, uma, o seu acabamento específico, e a outra, a alternância dos sujeitos falantes. Essas particularidades, vistas como critérios de acabamento do enunciado, propiciam a possibilidade de resposta. Veja, "o primeiro e mais importante dos critérios de acabamento do enunciado é a possibilidade de responder" (BAKHTIN, 2000, p. 299). A possibilidade de resposta está ligada ao enunciado em três fatores essenciais, que são eles: a- "o tratamento exaustivo do objeto do sentido"; b- "o intuito, o querer-dizer do locutor"; c- "as formas típicas de estruturação do gênero do acabamento.". Esses fatores, todos interligados no todo do enunciado, vão determinar as especificidades de cada esfera da comunicação verbal.

A especificidade do poema Eu, Etiqueta mostra que ele é um enunciado, e que é complexo e secundário. E como enunciado, está voltado e dirigido para alguém - o leitor. Todo ato de comunicação social está voltado para um propósito. Assim, pode-se admitir:

O enunciado está voltado não só para o seu objeto, mas também para o discurso do outro acerca desse objeto. A mais leve alusão ao enunciado do outro confere à fala um aspecto dialógico que nenhum tema constituído puramente pelo objeto poderia conferir-lhe. (BAKHTIN, 2000, p. 320). 
Toda relação dialógica transporta certas ideologias, pois todo enunciado ao conter signos é um agente ideológico. Portanto, "tudo que é ideológico possui um significado e remete a algo situado fora de si mesmo. Em outros termos, tudo que é ideológico é um signo. Sem signos não existe ideologia." (BAKHTIN, 1999, p. 31).

Esse poema além de relatar questões ideológicas de dominação, também reflete as questões ideológicas de dominados. Não há somente ideologia a favor de quem domina, mas também há ideologia de quem é dominado. Mais a frete, discutir-se-á melhor essa colocação, estudando os termos ideologia oficial e ideologia do cotidiano.

Todo produto de consumo pode ser transformado em signo, e todo signo é criado para atender uma função ideológica. Como função ideológica se entenderá: a política, a científica, a religiosa, e outras do mesmo suporte. Mas, h á a comunicação na vida cotidiana, que Bakhtin atribuía um grande valor, segundo ele "ela está diretamente vinculada aos processos de produção e, por outro lado, diz respeito às esferas das diversas ideologias especializadas $e$ formalizadas." (1999, p. 37). Assim, nota-se que as funções ideológicas transitam entre as classes sociais.

Outro aspecto importante de ser mencionado é a questão de onde surgem as ideologias? Na concepção bakhtiniana elas surgem da interação social, mas já para outras linhas do pensamento, como é o caso do idealismo e do psicologismo, ela se deriva da consciência, fato que Bakhtin (1999) considera um grande erro, pois ao situarem a ideologia na consciência, essas linhas, acabam transferindo o estudo da ideologia para o estudo da consciência. Esse erro produz uma confusão entre áreas do conhecimento, o produto ideológico material e social, é introduzido à força no quadro da consciência individual, e assim, para o idealismo a ideologia torna-se o "tudo", e para o psicologismo o "nada".

A ideologia é o material social particular dos signos, e os signos por sua vez, só podem aparecer num terreno interindividual, eles devem estar socialmente ligados, e pertencentes a um mesmo grupo. Dessa maneira, Bakhtin (1999) aponta que a consciência individual deve ser explicada a partir de um meio ideológico e não o contrário. A consciência é um fato sócio-ideológico, que foi transformada em depósito de problemas não resolvidos. Portanto, o idealismo e o psicologismo, ao colocarem o estudo da ideologia na consciência, afirmam que esta é um fato de consciência, e que o fato da exteriorização do signo é somente um revestimento do efeito anterior - a compreensão. Bakhtin (1999) afirma que tanto o idealismo, quanto o psicologismo, esquecem que a compreensão se manifesta a partir de um material semiótico, e que todo material semiótico é social. A ideologia não pode derivar da consciência, e esta última, só adquire forma e existência nos signos criados por um grupo organizado, ou seja, numa relação social. 
Sob esse viés, os signos como objetos naturais, podem adquirir vários sentidos, principalmente, pelo fato de que todo signo reflete e refrata uma outra realidade, que não a sua, por isso o campo do domínio do ideológico coincide com domínio dos signos. Ser ideológico é ter valor semiótico. Ainda, toda esfera ideológica possui um campo de criatividade, onde reflete ou refrata a realidade a sua maneira, independente da sua função no conjunto social, pois é justamente o seu caráter semiótico que liga todos os fenômenos ideológicos sob um mesmo plano (social), sendo todo signo um pedaço material de uma realidade. Por isso, por ser todo signo - e seus efeitos -, uma representação da realidade ou de um mundo exterior, ele se torna passível de estudo.

O que deve ficar claro, é que tudo que é ideológico possui um signo e remete a algo fora de si, ele reflete e refrata uma outra realidade. Sem signos não pode existir ideologia. Os signos têm um universo particular, que está ao lado dos fenômenos naturais, do material tecnológico e dos artigos de consumo, e cada signo ideológico, além de reflexo é também um fragmento material de uma realidade, seja esse fragmento, som, massa física, cor, movimento, etc. Todo signo ideológico, segundo Bakhtin (1999) na encarnação material, tem a sua realidade totalmente objetiva, portanto metodologicamente é unitário e objetivo. Todo signo é um fenômeno do mundo exterior.

A realidade ideológica é uma superestrutura situada imediatamente acima da base econômica. A consciência individual não está e nem constrói a superestrutura ideológica, ela está no social e nos signos ideológicos.

Portanto, compreender um signo, significa fazer relações com outros signos já conhecidos. E que na cadeia de criatividade ideológica, os signos deslocam-se para outros signos, criando novos signos. E essa cadeia ideológica estende-se de consciência individual para consciência individual num processo de interação social.

\section{Alienação e questões ideológicas}

Este poema retrata o poder da ideologia de uma classe sobre a outra, porém essa dominação não é explicita para todos, neste caso, esbarra-se na questão da alienação.

Para entender o termo alienação, voltar-se-á a filosofia grega, pois esta elaborou a teoria da causalidade, que explicava o movimento e as alterações da realidade social. Segundo Chauí (1994) essa explicação advinha de quatro causas, sendo: a material, a formal, a motriz ou eficiente e a final. Essas quatro causas não possuem o mesmo valor, e são dispostas numa relação de hierarquização, sendo em questão de valor de importância, da causa eficiente à causa final.

As quatro causas representam as mudanças, tanto qualitativas quanto quantitativas de um corpo, desde a locomoção a geração de novos corpos. O 
homem sempre procurou explicar suas transformações, e nessa procura, tentam compreender sua própria história, através da sua vida individual e social, estudando as relações existentes com a natureza e o sobrenatural. Chauí aponta que essas relações produzem representações, e que elas,

tenderão a esconder dos homens o modo real como suas relações sociais foram produzidas e a origem das formas sociais de exploração econômica e de dominação política. Esse ocultamento da realidade social chama-se ideologia. Por seu intermédio, os homens legitimam as condições sociais de exploração e de dominação, fazendo com que pareçam verdadeiras e justas. (CHAUÍ, 1994, p. 21).

Sob essa visão, é fácil aceitar que cada um possui o que é justo para ele possuir. Em outras palavras, o indivíduo não enxerga seu verdadeiro papel enquanto ser social e produtor, e ainda não se reconhece no processo de produção de seu próprio trabalho. Veja, Chauí (1994) aponta que Marx considerava o não reconhecimento da força de trabalho como alienação.

O indivíduo está alienado quando não reconhece em seu trabalho a causa formal e a causa eficiente, vendo apenas a causa material e a final, como sendo um resultado, não do seu trabalho, mas como um poder separado do seu e que, ameaça-o e domina-o. Para sintetizar esse conceito:

O trabalho alienado é aquele no qual o produtor não pode reconhecer-se no produto de seu trabalho, porque as condições desse trabalho, suas finalidades reais e seu valor não dependem do próprio trabalhador, mas do proprietário das condições do trabalho. (CHAUÍ, 1994, p. 55).

A partir dessa concepção de alienação, pode-se dizer que o poema $E u$, Etiqueta, relata sobre a alienação presente na sociedade brasileira. Pois, o indivíduo que não se reconhece frente aos produtos que usa, está alienado, e essa alienação é causada pelas ideologias da classe dominante, que detém os meios de produção e, portanto faz com que esses indivíduos não se reconheçam frente aos produtos que os rodeiam. Assim, o capital e os modos de produção separam os trabalhadores da realização de sua força de trabalho. Muitos dos que produzem as calças com os nomes que não são os seus, não possuem capacidade de comprá-las, justamente por causa da separação que resulta em dominação.

A alienação não permite que o real seja visto como ele é, e sim como um aparato de coisas, e essas coisas são oferecidas a nossa percepção como se fosse a própria realidade. Geralmente, as coisas tornam-se propriedades privadas, e essas propriedades privadas transformam a coisa em capital, ou seja, o indivíduo que está alienado, que não se reconhece no produto final, resultante de seu trabalho, e o seu próprio trabalho se torna uma coisa, denominada por Marx de força de trabalho, que é explorada por outros para se obter lucros (capital).

Essa força de trabalho resulta em outro conceito de Marx, que é o fetichismo, em poucas palavras, é à força de trabalho do homem se 
transformando em mercadoria. Para entender melhor, "a mercadoria será considerada a forma mais simples e mais abstrata do modo de produção capitalista" (CHAUÍ, 1994, p. 48). Como modo de produção a mercadoria tem por finalidade gerar lucros e/ou capital, mas não é tão simples quanto parece a primeira vista, a mercadoria não é apenas "uma "coisa", mais um valor", e esse valor pode ser entendido de duas formas, valor de uso e valor de troca, como valor de uso "parece valer por sua utilidade" e como valor de troca, "parece valer por seu preço de mercado" (CHAUÍ, 1994, p. 49).

O fetichismo ao criar a alienação, não deixando o indivíduo reconhecer na mercadoria sua força de trabalho, que ainda é mencionada por Chauí (1994) como força de trabalho não paga, também apaga a possível visualização do processo de coisificação.

Esse processo, também conhecido como reificação, é muito bem utilizado por Drummond, pois o fechamento do poema se dá:

"Meu nome é a coisa.

Eu sou a Coisa, coisamente."

O poeta consegue realizar uma crítica acerca das relações sociais, tão bem fundada, que reproduz conceitos de grandes pensadores em poesia, sem perder a maestria no compasso das palavras que são regidas por uma realidade controlada por processos que pretendem dominar as pessoas. Complementando as citações anteriores:

A alienação, reificação, fetichismo: é esse processo fantástico no qual as atividades humanas começam a se realizar como se fossem autônomas ou independentes dos homens e passam a dirigir e comandar a vida dos homens, sem que estes possam controlá-las. (CHAUí, 1994, p. 58)

Portanto, de forma sutil o poema fala de alienação, de reificação e de fetichismo, pois retrata, o não reconhecimento de um indivíduo como indivíduo que produz com sua força de trabalho o que consome.

\section{Ideologia do cotidiano e ideologia oficial}

É muito importante estabelecer certo entendimento para o termo ideologia, mas o fundamental para este trabalho, é conseguir mostrar o papel que este termo tem no pensamento Bakhtin.

Para o pensador russo, as quatro causas não é a melhor resposta para a questão de como a infra-estrutura determina a ideologia, para ele, "sempre que se coloca a questão de saber como a infra-estrutura determina a ideologia, encontramos a seguinte resposta que, embora justa, mostra-se por demais genérica e por isso ambígua: "a causalidade"." (BAKHTIN, 1999, p. 39). A ideologia é um conjunto único e indivisível cujos elementos, sem exceção, reagem às transformações da infra-estrutura, assim de forma dialética, vê-se que ele não 
entende ideologia como algo pronto e acabado.

Para ficar mais claro, devido à utilização neste tópico dos termos, infraestrutura e superestrutura, grosso modo, entender-se-á pelo primeiro, de forma dialética, como modo de produção (a palavra não pode ser vista como infraestrutura). Já o segundo, deve ser visto como: a economia, o estado, a linguagem, a arte, entre outros.

Após o amparo dessa explicação, ver-se-á que o material semiótico visualizado nos signos, deve ter sua especificidade estudada não somente como referência ao seu valor denotativo racional, sem mediar às relações entre as estruturas, veja, o problema da relação recíproca entre infra-estrutura e a superestrutura, para Bakhtin (1999) deve ser esclarecida pelo estudo do material verbal. A questão então é saber como a infra-estrutura (realidade) determina o signo, e como o signo reflete e refrata a realidade em transformação.

Dessa maneira, as relações sociais, como a interação social e verbal, estabelecem os processos dialéticos do signo, que para Bakhtin (1999) correspondem: a- não separar a ideologia da realidade material do signo (não colocar na consciência); b- não dissociar o signo das formas concretas da comunicação social (fora disso ele é objeto físico); c- não dissociar a comunicação e suas formas de sua base material (infra-estrutura).

Muito se fala de ideologia neste trabalho, porém ainda não foi realizada nenhuma definição do que vem a ser ideologia, falou-se de vários aspectos que envolvem a ideologia, mas nenhum explicativo a esse termo. Portanto, agora se dará uma breve explanação, visto a importância do entendimento desta questão dentro deste estudo.

Chauí (1994) aponta que Marx e Engels consideravam a alienação como forma inicial da consciência, e que a divisão social do trabalho se tornava completa quando havia a separação entre trabalho material e espiritual, e que somente como essa divisão a consciência podia representar algo sem ser algo real. Assim, para eles nascia a ideologia, isto é,

o sistema ordenado de idéias ou representações e das normas e regras como algo separado e independente das condições materiais, visto que seus produtores - os teóricos, os ideólogos, os intelectuais - não estão diretamente vinculados à produção material das condições de existência. (CHAUÍ, 1994, p. 65).

Em outras palavras se pode dizer segundo essa citação - dominação de uma classe sobre a outra, que resulta na contradição -, a autora ainda cita que em termos de materialismo histórico dialético era impossível compreender a origem e as funções da ideologia sem compreender as lutas de classes, pois " $a$ ideologia é um dos instrumentos da dominação de classe e uma das formas de luta de classes" (CHAUÍ, 1994, p. 86). A ideologia na luta de classes, para os materialistas, além de ser objetivamente possível por causa da alienação, tem o papel de ocultar a verdade, ou seja, ocultar a dominação real, por esses fatos, 
eles acreditam que ela deve ser destruída. A grande função da ideologia é impedir que a classe dominada se revolte contra a que domina, assim, a classe que está no poder cria mecanismos para legitimar sua dominação, por exemplo, o Estado, que segundo a autora, mostra que as leis, representam as vontades de todos, legitimando seu poder como justo e bom.

A partir dessa visão, a ideologia é a transformação das idéias da classe que domina em idéias de todas as classes, ora quem tem o poder de controlar o Estado, a Economia, a Política, tem o poder de dominar as classes sociais. E quando as idéias de uma classe são absorvidas por outras, tem-se a criação de universais abstratos. A ideologia para o materialismo dialético é uma ilusão, porém não pode ser considerada a termos como: ficção, fantasia, erro, falsidade, e etc. Ela deve ser entendida por abstração e inversão. Assim, abstração

é o conhecimento de uma realidade tal como se oferece à nossa experiência imediata, como algo dado, feito e acabado que apenas classificamos, ordenamos e sistematizamos, sem nunca indagar como tal realidade foi concretamente produzida. (CHAUÍ, 1994, p. 104).

Dessa maneira, pode-se entender que uma realidade existe porque foi construída por um sistema determinado de condições de dominação, que não se deixa visualizar e indagar pela classe que é dominada. A partir disso, tem-se a inversão que "é tomar o resultado de um processo como se fosse seu começo, tomar os efeitos pelas causas, as conseqüências pelas premissas, o determinado pelo determinante" (CHAUÍ, 1994, p. 104).

A abstração não deixa que se visualize a realidade como ela realmente é, e a inversão faz com se aceite as situações pelas causas erradas. A ideologia deixa a base da realidade invertida, ou seja, de ponta-cabeça, esse fato pode ser visualizado no que os materialistas chamam de aparência social.

$\mathrm{O}$ poema $E$ u, Etiqueta relata em seus versos, abstração e inversão. Abstração, no caso do locutor (autor) não se reconhecer em si mesmo, e inversão quando se reconhece e aceita como anúncio.

A leitura desse texto mostra outras relações de abstração e inversão, fato que o condicionou a compor este estudo, visto a riqueza na demonstração das questões abordadas aqui. Mas, para fazer uma análise mais coerente, devem ser buscadas outras definições para ideologia.

Então, entrar-se-á na obra de Eagleton, que indica 16 formas variadas de significação para esse termo. Porém, não se versará sobre todas. Para iniciar, Eagleton exemplifica que ideologia não é um fato rígido e fixo, preso as idéias de uma dada classe, para tanto cita uma conversa cotidiana, mostrando como se pode entender uma significação ideológica, pois ao explicar, revela que falar ou avaliar ideologicamente uma conversa corriqueira de maneira esquemática é ter uma visão simplista do mundo. A partir disso surge à questão, que se tudo que chamamos de ideológico é racionalista. Uma definição que se pode chegar a respeito da ideologia, é que ela não é um conjunto de idéias e normas fixas, pois 
nem todo conjunto de idéias e normas fixas é ideológico. Veja, o exemplo utilizado por Eagleton para tal afirmação:

posso ter convicções bastantes inflexíveis com respeito a como escovar meus dentes, submetendo cada um deles, individualmente, a um número exato de escovações e preferindo sempre escovas cor-de-malva, mas, na maioria dos casos, seria estranho qualificar tais opiniões de ideológicas (1997, p. 17).

O autor se refere a essa citação como patológica, explicando que para ser possível uma adequação ideológica, seria necessário dizer que é preciso "escovar os dentes porque se os ingleses não se mantiverem saudáveis os soviéticos dominarão nossa nação débil e desdentada” (1997, p. 17). Dessa maneira, seria ideologicamente motivado por um comportamento, que se refere não apenas para um sistema de crenças, mas também a questões acerca do poder.

Geralmente, pode-se entender que a ideologia serve como instrumento de legitimação do poder de uma classe sobre a outra, resultando numa "mistificação" que pode ser vista como uma camuflagem ou repressão dos conflitos sociais, dando origem ao conceito de ideologia como uma resolução imaginária (acima das relações de poder) de contradições existentes entre as classes.

Essa concepção, segundo Eagleton, “apresenta pelo menos dois grandes problemas", em primeiro lugar, "nem todo corpo de crenças normalmente denominado ideológico está associado a um poder político dominante" (EAGLETON, 1997, p. 19), em segundo, que uma teoria não poderia abranger tudo, pois perderia seu valor, assim,

\footnotetext{
para que um termo tenha significado, é preciso que se possa especificar o que, em determinadas circunstâncias, seria considerado o outro dele - o que não significa, necessariamente, especificar algo que seja sempre e em qualquer parte o outro dele. (...) então a palavra ideologia deixa de particularizar algo e perde totalmente sua capacidade de informar - da mesma forma que se cada amostra do comportamento humano, seja ela qual for, inclusive a tortura, fosse considerada um exemplo de compaixão, a palavra compaixão se reduziria a um significante vazio. (EAGLETON, 1997, p. 20).
}

Então, todo corpo de crenças e idéias não podem ser totalmente fixos e rígidos, e não representam necessariamente os grupos que estão no poder, para ser ideológico segundo esta última concepção, o significado deve especificar o outro dele. Portanto, vê-se que nem tudo pode ser encarado como ideológico. Pode-se dizer aqui, que a idéia central do poema Eu, Etiqueta, não precisa ser vista como um simples relato da ideologia dominante, e sim como uma ideologia do poeta. O fato importante a se retirar dessa concepção de ideologia, é que ela mostra outra visão a respeito do termo, deixando claro, que não há somente um lado da moeda.

Outra definição pertinente de ideologia, apontada por Eagleton (1997), é a de Althusser na questão de "relações vivenciadas", onde esse diz que a ideologia é uma organização específica de práticas significantes que vão 
constituir os seres humanos como sujeitos sociais e que produzem as relações vivenciadas mediante as quais sujeitos vinculam-se às relações de produção dominantes em uma sociedade, portanto, essa explicação de ideologia faz menção à nossa relação afetiva e inconsciente com o mundo.

Segundo Eagleton (1997), pode-se ainda definir a ideologia de seis maneiras diferentes. Grosso modo, primeiramente, pode-se referir a ela como um processo material geral de produção de idéias, crenças e valores na vida social; um segundo significado, remete-a para crenças que simbolizam as condições e experiências de vida de um grupo ou classe específica; em terceiro, tratar da promoção e legitimação dos interesses de tais grupos sociais em face de interesses opostos; em quarto, uma ênfase na promoção e legitimação de interesses setoriais, restringindo-a, porém, às atividades de um poder social dominante; em quinto, significa que as idéias e crenças que ajudam a legitimar os interesses de um grupo ou classe dominante, mediante, sobretudo a distorção e a dissimulação; e por último, cuja ênfase de significado recai sobre a s crenças falsas ou ilusórias, considerando-as, porém oriundas não dos interesses de uma classe dominante, mas da estrutura material do conjunto da sociedade como um todo.

Agora, após a apresentação dessas definições, levanta-se a questão, qual é a posição de Bakhtin sobre ideologia? Para tentar responder essa pergunta, procurou-se apoio no texto Ideologia de Valdemir Miotello, onde é apontada a existência de duas formas de ideologia para os marxistas, sendo uma a "ideologia oficial" e a outra "ideologia do cotidiano". Segundo esse autor, Bakhtin e seu círculo puderam estabelecer, bem a seu gosto, uma relação dialética entre essa duas formas:

\footnotetext{
De um lado, a ideologia oficial, como estrutura ou conteúdo, relativamente estável; de outro, a ideologia do cotidiano, como acontecimento, relativamente instável; e ambas formando o contexto ideológico completo e único, em relação recíproca, sem perder de vista o processo global de produção e reprodução social. (MIOTELLO, 2008, p. 169).
}

O ponto que se deve fixar, é que para compreender as relações sociais e ideológicas em Bakhtin, é necessário entendê-las de forma dialética e não causal. Essa concepção de ideologia, dividida em dois pólos (estáveis e instáveis), é a maneira ideal encontrada pelo pensador russo para criar uma conexão de estudo entre ideologia e o estudo da linguagem.

Para Bakhtin (1999), a ideologia é o material social particular dos signos, e os signos por sua vez, só podem aparecer num terreno interindividual, e devem estar socialmente ligados, pertencentes a um mesmo grupo. E, a partir desse grupo, pode-se ver a comunicação cotidiana, que não pode ser vinculada a nenhuma esfera ideológica particular. A comunicação cotidiana representa a ideologia do cotidiano, que tem como material mais privilegiado de sua comunicação à palavra, e esta por sua vez, está sempre ligada ao ato ideológico. 
Isso não significa que ela não possa ser substituída, existem signos que não podem ser exprimidos por palavras de modo adequado, alguns exemplos citados por Bakhtin remetem à composição musical e a representação pictórica.

A ideologia do cotidiano deve ser vista como encontros causais, acontecimentos dispersos e rotineiros no conjunto de comunicação social, nascendo como forma primaria de ideologia, onde a "mudança se dá de forma lenta, visto que os signos estão diretamente em contato com os acontecimentos socioeconômicos" (MIOTTELLO, 2008, p. 173). Já a ideologia oficial, pode ser observada como um sistema especializado de ideologia, onde circulam conteúdos como a moral, a arte, o direito, a religião, e etc. A ideologia oficial exerce forte influência no jogo social, "por ser o sistema de referência constituído e apossado pela classe dominante" (MIOTTELO, 2008, p. 174).

Nesse sentido, a ideologia sempre será vista como um sistema de representação da sociedade, sendo do cotidiano ou oficial, constituída das interações existentes entre grupos sociais. Assim, reportando ao início do trabalho, pode-se dizer que na ideologia do cotidiano, há a construção de um enunciado simples e primário, de onde surgem signos que representam uma ideologia. E que esse enunciado junto de seus signos, ao se transformar em outros enunciados, complexos e secundários, perde sua natureza com a realidade existente, refletindo e refratando uma outra realidade, agora composicional de uma ideologia oficial.

\section{Considerações finais}

O fato ao qual se quer depreender por meio desta pesquisa, é a influência que enunciados, signos e ideologia exercem sobre a interação social. Através dos conceitos apresentados, busca-se criar um campo de entendimento, onde seja possível assimilar o máximo do pensamento de Bakhtin a respeito desses termos.

Para fechar, é importante dizer que o poema Eu, Etiqueta é um enunciado concreto, com uma enunciação poética que sintetiza um momento histórico, onde o poeta mostra as relações existentes da sociedade em que vive propiciando uma interação com os destinatários do seu discurso, pois a enunciação deste poema como expressão semiótica se destina a duas orientações, uma, "em direção ao sujeito", e a outra, a partir dele "em direção a ideologia" (BAKHTIN, 1999, p. 60). E que, a palavra por ser o material semiótico privilegiado, comporta duas faces, ela parte de alguém para um outro e esse fato produz o produto da interação verbal.

O signo por sua vez, é criado por uma função ideológica precisa e permanece inseparável dela. A palavra ao contrário, é neutra a qualquer função ideológica específica. Por isso ela pode preencher qualquer função ideológica: estética, científica, religiosa, etc. Bakhtin (1999) apontava que a base de estudo 
marxista enquanto método sociológico deve partir do estudo da palavra por uma filosofia da linguagem concebida como filosofia do signo ideológico.

Portanto, pode-se dizer também que o poema Eu, Etiqueta é um enunciado, complexo e secundário, por estar contido em uma obra destinada à leitura. Os signos criados pelo poeta refletem e refratam uma realidade, e no processo de leitura, esses signos tornam-se outros signos, refletindo e refratando outras realidades. E como toda obra, a enunciação deste poema se destina a uma resposta, a uma compreensão responsiva que é esperada pelo autor.

As mensagens publicitárias, as estampas de produtos, os próprios produtos, a linguagem utilizada, a língua (seja qual for), os imperativos, tudo que o poeta cita como objetos, na verdade, são signos, que se oferecem "como signos dos outros", ora, todas as mensagens que as pessoas portam em seus objetos pessoais, trazem em si a mesma característica, são signos que as pessoas veiculam sem estar ganhando para anunciar, e como todo signo, possui um significado que remete a algo fora de si mesmo, assim, pode-se perceber que o que está sendo veiculado nessas mensagens, por se tratar de signos, nada mais é do que ideologia.

\section{Referências}

ANDRADE, Carlos Drummond. Corpo. Rio de Janeiro: Record, 1984. BAKHTIN, Mikhail. Estética da criação verbal. São Paulo: Martins Fontes, 2000. . Marxismo e filosofia da linguagem. São Paulo: Hucitec, 1999.

CHAUÍ, Marilena S. O que é ideologia. São Paulo: Brasiliense, 1994.

EAGLETON, Terry. Ideologia. São Paulo: Edunesp/Boitempo, 1997.

MIOTELLO, Valdemir. Ideologia. In: BRAIT, Beth (Org.). Bakhtin: ConceitosChave. São Paulo: Contexto, 2008. 